\title{
The increasing prevalence of myopia in junior high school students in the Haidian District of Beijing, China: a 10-year population-based survey
}

Yan $\mathrm{Li}^{1}$, Jia Liu ${ }^{1,2^{*}}$ and Pengcheng $\mathrm{Qi}^{1}$

\begin{abstract}
Background: Myopia is a leading cause of preventable blindness. Although, multiple cross-sectional epidemiological studies have confirmed that there is a high prevalence of myopia in high school-aged students in China. However, few longitudinal studies have been performed to assess junior high school students. In the present study, we investigate changes in the prevalence of myopia in third year junior high school (grade 9) students in the Haidian District of Beijing, China, from 2006 to 2015.

Methods: A retrospective, longitudinal cohort study was performed over 10 years. A total of 37,424 third-year middle school (grade 9) students from 8 junior high schools in Haidian district, Beijing, were included. Participants underwent a comprehensive ophthalmic examination in which they were evaluated using autorefraction under cycloplegia and submitted to retinoscopy to assess accuracy. According to the spherical equivalent refraction (SER) of the right eye, subjects were separated into the following groups: non-myopia, $-0.5 \leq$ SER diopters (D); low myopia, $-3.0 \leq$ SER $<-0.5$ D; moderate myopia, $-6.0 \leq$ SER $<-3.0$ D; and high myopia, SER > -6.0 D. The following characteristics were measured: refractive error; the proportion of subjects with non- myopia, low myopia, moderate myopia and high myopia; and the difference in the prevalence of myopia between male and female subjects.
\end{abstract}

Results: From 2006 to 2015, the prevalence of non-myopia (from 44.05\% to 34.52\%) and low myopia (from $32.27 \%$ to $20.73 \%$ ) decreased, while the prevalence of moderate myopia (from 19.72\% to 38.06\%) and high myopia (from 3.96\% to 6.69\%) significantly increased. For refractive error, the worse eye was $-2.23 \pm 2.42 \mathrm{D}$ (median, -1.75 ; range -12.75 to +8.50 ) in 2006 and $-3.13 \pm 2.66 \mathrm{D}$ (median, -2.75 ; range -12.75 to +8.50 ) in 2015. When the entire population was considered, the overall prevalence of myopia increased from $55.95 \%$ in 2005 to $65.48 \%$ in 2015. There was a significant positive relationship between the year and the prevalence of myopia in both girls and boys. Girls were more likely than boys to have myopia (odds ratio, 1.43 [95\% Cl, 1.14-1.96]), especially moderate myopia, and the prevalence of moderate and high myopia were higher in girls than in boys.

Conclusions: During the last 10 years, the prevalence of myopia significantly increased on an annual basis among third-year junior high school students in the Haidian District of Beijing, China. The total prevalence of myopia was significantly higher in girl than in boy participants. The refractive status of this age group deserves particular attention.

Keywords: Myopia, Prevalence, Junior high school, Haidian District, Beijing

\footnotetext{
* Correspondence: 41379226@qq.com

'Department of Ophthalmology, College of Optometry, Peking University Health Science Center; Center of Optometry, Peking University People's Hospital; Beijing Key Laboratory of Diagnosis and Therapy of Retinal and Choroid Diseases, Beijing 100044, China

${ }^{2}$ Key Laboratory of Vision Loss and Restoration, Ministry of Education,

Department of Ophthalmology, Peking University People's Hospital, Xizhimen

South Street 11, Xi Cheng District, Beijing 100044, China
} 


\section{Background}

Myopia is a leading worldwide cause of preventable blindness, especially in children and young adults $[1,2]$. Recent epidemiological studies have revealed that the prevalence of myopia is rapidly increasing globally, especially in East and Southeast Asian countries. For example, in Taiwan, the prevalence of myopia among 16 - to 18-year-old children increased from $74 \%$ in 1983 to $84 \%$ in 2000 [3]. In Japan, the prevalence among 7year-olds increased from $39 \%$ in 1984 to $59 \%$ in 1996 [4]. Additionally, a series of surveys demonstrated that the prevalence among teenagers is approximately $96.5 \%$ in Korea [5, 6], 81.6\% in Singapore [7], and 95.5\% in Shanghai, China [8].

In China, the school education system includes preschool, primary school, junior high school, and senior high school. Since 1986, China's governmental Ministry of Education has implemented 9 years of compulsory education, including 6 years of primary school (grades 1 to 6) education and 3 years of junior high school (grades 7 to 9) education [9]. At the end of the third year of junior high school, most of the students continue to senior high school (grades 10 to 12), which is followed by entering a university, especially in urban cities. The remaining students who do not go to senior high school go to work, usually in rural areas. Because a high level senior high school is associated with a higher likelihood of entering a distinguished university and because attending such a university is viewed as an indicator of access to better work opportunities, grade 9 and grade 12 students are under a particularly high amount of study pressure. Previously, multiple cross-sectional epidemiological studies have confirmed that there is a high prevalence of myopia in high school-aged students in China [10-12]. Additionally, several studies have focused on the incidence of myopia in grade 12 students and shown that the prevalence of myopia is estimated to be approximately $80 \%$ in 17-year-olds [9]. However, relatively few longitudinal studies have been performed to assess junior high school (grade 9) students, and largescale retrospective studies are the most accurately methods to evaluate changes over time [4].

In the present study, we analyzed longitudinal data obtained from students of the Haidian District of Beijing, China from 2006 to 2015 to track changes in the prevalence of myopia in third-year junior middleschool (grade 9) and to evaluate current trends with the aim of providing guidance for the future management of myopia in China.

\section{Methods}

\section{Study population and sampling}

The present retrospective, longitudinal cohort study was conducted in the Haidian District of Beijing, China from
September 2006 to September 2015. Out of 73 junior high schools, 8 were randomly selected. All third-year students in the selected schools were invited to participate in the study, and the refractive status of all of the evaluated students were routinely collected each year. The survey was conducted by a research group that consisted of two qualified ophthalmologists and two optometrists. All participants were registered, including their name, sex, age, and the name of their school.

\section{Ethics, consent and permissions}

Ethical approval was obtained from the Ethics Review Board and the Ethics Committee of Peking University People's Hospital. Informed written consent as obtained from at least one parent or guardian of each child. The study adhered to the guidelines of the Declaration of Helsinki.

\section{Eye examination and VA measurements}

The ophthalmologic examination consisted of measurements of uncorrected visual acuity (VA) and bestcorrected visual acuity (BCVA), a slit lamp-based examination of the anterior ocular segment by an ophthalmologist, assessments of tonometry (noncontact tonometer; Canon TX-F Full-Auto Tonometer; Canon Co., Tokyo, Japan), ocular motility, and binocularity, and an evaluation to determine the presence of strabismus. Cycloplegia was achieved by instilling at least five drops of $1 \%$ cyclopentolate (Alcon, Fort Worth, TX, USA) in intervals of 5 min before obtaining autorefraction measurements (ARK-900; Nidek, Tokyo, Japan). During the refractometry, each eye was measured at least three times [5].

VA was performed at $5 \mathrm{~m}$ in examination rooms that were illuminated to approximately $500 \mathrm{~lx}$ using a Standard Logarithmic Visual Acuity E chart (Wenzhou Xingkang Medical Technology Co., Ltd., Zhejiang, China). The BCVA was recorded as the smallest size at which at least three optotypes were correctly identified. BCVA was measured using subjective refraction by two senior experienced optometrists.

The spherical equivalent refraction (SER) was calculated as the spherical value of the refractive error plus half of the cylindrical value. Using the SER for the worst eye of each subject, the refractive error (RE) was defined as non-myopia $(-0.5 \leq$ SER diopters (D), including hyperopia and emmetropia), low myopia $(-3.0 \leq$ SER $<-$ $0.5 \mathrm{D})$, moderate myopia $(-6.0 \leq \mathrm{SER}<-3.0 \mathrm{D})$, or high myopia (SER > -6.0 D).

\section{Statistical analysis}

The data were analyzed using the SPSS software program (SPSS, Chicago, IL, USA) and GraphPad Prism software, version 5.0 (GraphPad Software Inc., San 
Diego, CA, USA). In this report, all data were analyzed using the worse eye of each participant. Median [interquartile range (IQR)] and percentage values were reported in the descriptive analyses for continuous and categorical variables, respectively. Chi-squared tests were used to compare differences in myopia between boy and girls. Odds ratios (ORs) and their 95\% confidence intervals $(\mathrm{CI})$ are presented. All $P$ values were obtained using $t$ tests, and a value less than 0.05 was considered statistically significant.

\section{Results}

\section{Characteristics of the study population}

Over 10 years, 37,424 eligible students were invited to participate (Additional file 1). The students had a mean age of $15.25 \pm 0.46$ years old (median: 15.6 years old; range, 14-16 years old), and 17,925 of the students were boys $(47.90 \%)$, while 19,499 were girls $(52.10 \%)$. Table 1 shows the demographic characteristics of the study participants.

\section{Change in refractive error}

The mean spherical equivalent refractive error (SERE) significantly increased during the 10 -year study period from $-1.92 \pm 2.26 \mathrm{D}$ [media -1.50 , range -12.75 to +8.50 ] in right eyes, $-2.03 \pm 2.32 \mathrm{D}$ [media -1.50 , range -11.25 to +7.25 ] in left eyes and $-2.23 \pm 2.42 \mathrm{D}$ [media -1.75 , range -12.75 to +8.50 ] in worse eyes in 2006 to $-2.75 \pm 2.51 \mathrm{D}$ [media -2.50 , range -12.75 to +8.25 ] in right eyes, $-2.95 \pm 2.61 \mathrm{D}$ [media -2.75 , range -13.00 to +10.75 ] in left eyes and $-3.13 \pm 2.66 \mathrm{D}$ [media -2.75 , range -12.75 to +8.50 ] in worse eyes in 2015 (Table 2). The obtained refractive errors were not normally distributed $(P<0.001)$.

Table 1 Demographic characteristics of the participants in the Haidian District of Beijing, China

\begin{tabular}{lll}
\hline Year & $N^{a}$ & Gender (Boys/Girls) (\%) \\
\hline 2006 & 3657 & $1742 / 1915(47.63 / 52.37)$ \\
2007 & 3615 & $1720 / 1895(47.58 / 52.42)$ \\
2008 & 3662 & $1728 / 1934(47.19 / 52.81)$ \\
2009 & 3697 & $1833 / 1864(49.58 / 50.42)$ \\
2010 & 3897 & $1853 / 2044(47.55 / 52.45)$ \\
2011 & 3784 & $1926 / 1858(50.90 / 49.10)$ \\
2012 & 3816 & $1752 / 2064(45.91 / 54.09)$ \\
2013 & 3787 & $1816 / 1971(47.95 / 52.05)$ \\
2014 & 3833 & $1783 / 2050(46.52 / 53.48)$ \\
2015 & 3676 & $1772 / 1904(48.20 / 51.80)$ \\
Total & 37,424 & $17,925 / 19499(47.90 / 52.10)$ \\
\hline
\end{tabular}

${ }^{\mathrm{a}} \mathrm{N}=$ number

\section{Incidence of myopia}

The prevalence of myopia was defined as a refractive error $\leq-0.50$ diopters, as described in the Methods section. According to our data, the proportion of students with non-myopia (44.05\% in 2006 to $34.52 \%$ in 2015) and low myopia (32.27\% in 2006 to $20.73 \%$ in 2015 ) decreased during the study period, whereas there was a significant increase in the proportion of students with moderate myopia (19.72\% in 2006 to $38.06 \%$ in 2015 ) and high myopia (3.96\% in 2006 to $6.69 \%$ in 2015). Overall, the prevalence of myopia increased significant from $55.95 \%$ in 2006 to $65.48 \%$ in 2015 (a 9.53\% increase, $P<0.001$, Fig. 1, Fig. 2 , and Table 3). The moderate high myopia subgroup increased by $18.34 \%$, and this was the most significantly increase out of all of the subgroups (Fig. 1b, Table 2). The prevalence of moderate and high myopia exceeded that of low myopia after 2009 and surpassed the prevalence of non-myopia after 2012 (Fig. 1b).

\section{Males versus females}

In a univariate analysis, girls were significantly $(P<0.001)$ more myopic and more likely to have myopia than boys (Fig. 2, Chi-squared test, $P<0.05$ for each year except 2011; and Fig. 3). The percentage of students with myopia was already $30.57 \%$ in girls in 2006 , and this proportion subsequently increased, reaching $35.85 \%$ in 2015 (a 5.28\% increase, $P<0.001$ ). In contrast, the percentage of boys with myopia increased from $25.38 \%$ in 2006 to $29.62 \%$ in 2015 (a $4.24 \%$ increase, $P<0.001$ ). In 2015 , the prevalence of myopia was $6.23 \%$ higher in girls than in boys. Between females and males, the odds ratio (OR, 95\% confidence interval $(\mathrm{CI})$ ) for overall myopia was 1.43 (95\% CI: $1.14-1.96, P=0.007$ ).

In both boys and girls, the proportion of students with low myopia decreased significantly between 2006 and 2015 (both $P<0.001$ ), and the changes in the proportions between the two subgroups occurred in parallel (Fig. 4). However, in the female subgroup, the prevalence of students with moderate and high myopia increased more than in the male group. In the moderate myopia group, the prevalence in girls increased by $9.14 \%$, from $12.81 \%$ in 2006 to $21.95 \%$ in 2015 (Fig. 4c), and this was more significant than the increase in the boys group $(P<0.001)$. However, the prevalence of high myopia in girls increased by $0.53 \%$, from $2.98 \%$ in 2006 to $3.51 \%$ in 2015 (Fig. 4d), but there is no statistically significant change in the boys group, which increased by $0.95 \%$, from $0.98 \%$ in 2006 to $1.93 \%$ in 2015 . In the girls subgroup, the prevalence of moderate myopia surpassed the prevalence of low myopia after 2009, whereas in the boys group, this event occurred after 2012 (Fig. 3). These findings indicate that females are more likely than males to develop moderate myopia $(P<0.001)$. 
Table 2 Refractive error (diopters; spherical equivalent) in participants in the Haidian District of Beijing, China

\begin{tabular}{|c|c|c|c|c|c|c|c|c|c|c|c|c|}
\hline \multirow[b]{2}{*}{ Year } & \multicolumn{4}{|c|}{ Right eye } & \multicolumn{4}{|c|}{ Left eye } & \multicolumn{4}{|c|}{ Worse eye } \\
\hline & Mean & Median & $\mathrm{SD}^{\mathrm{a}}$ & $\operatorname{Min}^{b}, \operatorname{Max}^{c}$ & Mean & Median & $S D^{a}$ & $\operatorname{Min}^{b}, \operatorname{Max}^{c}$ & Mean & Median & $\mathrm{SD}^{\mathrm{a}}$ & $\operatorname{Min}^{b}, \operatorname{Max}^{c}$ \\
\hline 2006 & -1.92 & -1.50 & 2.26 & $-12.75,+8.50$ & -2.03 & -1.50 & 2.32 & $-11.25,+7.25$ & -2.23 & -1.75 & 2.42 & $-12.75,+8.50$ \\
\hline 2007 & -1.97 & -1.50 & 2.30 & $-13.00,+7.75$ & -2.15 & -1.75 & 2.42 & $-13.25,+8.25$ & -2.30 & -2.00 & 2.51 & $-13.25,+8.25$ \\
\hline 2008 & -2.07 & -1.75 & 2.26 & $-12.50,+8.25$ & -2.30 & -2.00 & 2.43 & $-10.75,+7.75$ & -2.45 & -2.25 & 2.47 & $-12.50,+8.25$ \\
\hline 2009 & -2.25 & -1.75 & 2.35 & $-11.00,+9.50$ & -2.46 & -2.25 & 2.43 & $-12.50,+6.75$ & -2.59 & -2.25 & 2.49 & $-12.50,+9.50$ \\
\hline 2010 & -2.34 & -2.00 & 2.43 & $-11.75,+10.25$ & -2.53 & -2.25 & 2.54 & $-11.75,+8.25$ & -2.68 & -2.50 & 2.60 & $-11.75,+10.25$ \\
\hline 2011 & -2.42 & -2.00 & 2.46 & $-12.00,+7.25$ & -2.62 & -2.25 & 2.57 & $-12.75,+9.75$ & -2.76 & -2.50 & 2.64 & $-12.75,+9.75$ \\
\hline 2012 & -2.47 & -2.00 & 2.45 & $-11.25,+8.75$ & -2.70 & -2.50 & 2.58 & $-11.50,+10.75$ & -2.86 & -2.50 & 2.63 & $-11.50,+10.75$ \\
\hline 2013 & -2.54 & -2.25 & 2.50 & $-12.50,+7.75$ & -2.78 & -2.50 & 2.60 & $-13.00,+7.25$ & -2.93 & -2.75 & 2.66 & $-13.00,+7.75$ \\
\hline 2014 & -2.68 & -2.50 & 2.46 & $-13.00,+9.25$ & -2.89 & -2.75 & 2.55 & $-13.25,+8.25$ & -3.07 & -2.75 & 2.61 & $-13.25,+9.25$ \\
\hline 2015 & -2.75 & -2.50 & 2.51 & $-12.75,+8.25$ & -2.95 & -2.75 & 2.61 & $-12.75,+8.50$ & -3.13 & -2.75 & 2.66 & $-12.75,+8.50$ \\
\hline Total & -2.34 & -2.00 & 2.42 & $-13.00,+10.25$ & -2.54 & -2.25 & 2.52 & $-13.00,+10.75$ & -2.70 & -2.50 & 2.59 & $-13.25,+10.75$ \\
\hline
\end{tabular}

${ }^{\mathrm{a}} \mathrm{SD}=$ standard deviation; ${ }^{\mathrm{b}}$ Min $=$ minimum; ${ }^{\mathrm{c}}$ Max $=$ Maximum

\section{Discussion}

There are three main findings in the present study, which was performed from 2006 to 2015 in a population of third-year students (aged 15 to 16 years old) in junior high school (grade 9) in the Haidian District of Beijing, China. First, the mean spherical equivalent refractive error and prevalence of myopia increased significantly, according to measurements of cycloplegic autorefractioin between baseline and follow-up examinations. Second, the proportion of students with hyperopia, emmetropia and low myopia decreased over the study period, while the prevalence of myopia increased

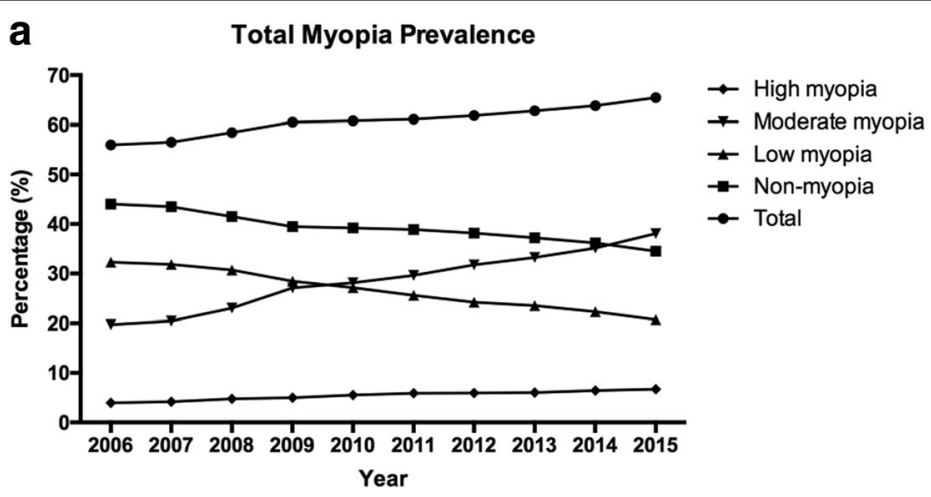

b

Total Myopia Prevalence

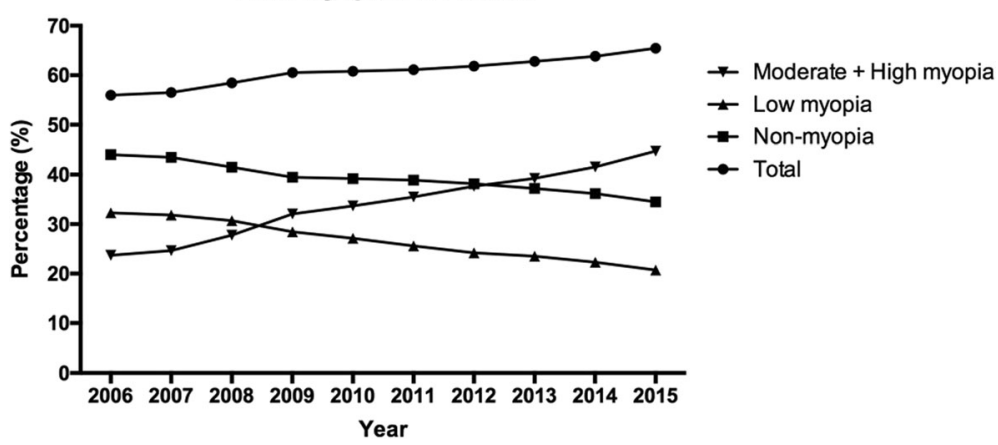

Fig. 1 Prevalence of non-myopia and myopia in the whole group. a The incidence of non-myopia, low myopia, moderate myopia, and high myopia are presented. The total myopia group was defined using a refractive error $>-0.50$ diopters and included students with low myopia, moderate myopia, and high myopia. Overall, the prevalence of myopia increased significantly. $\mathbf{b}$ The total myopia group was defined using a refractive error $>-3.0$ diopters and included the moderate myopia and high myopia groups 


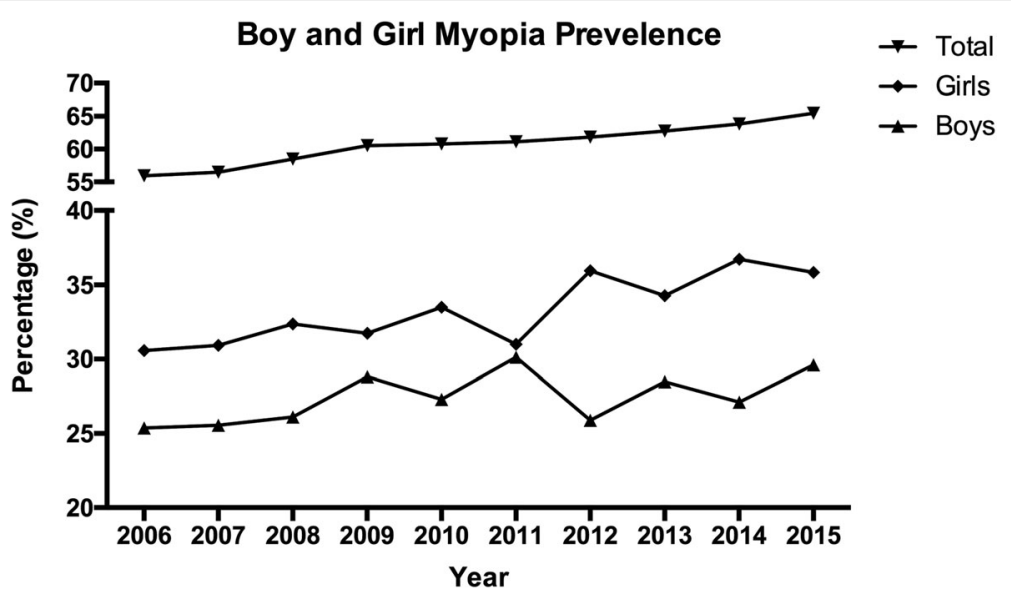

Fig. 2 Prevalence of myopia in boys and girls. In a univariate analysis, girls were significantly more myopic and more likely to have myopia than boys from 2006 to 2015

Table 3 Prevalence of myopia among third-year students in junior high school in Haidian District, Beijing, China

\begin{tabular}{|c|c|c|c|c|c|c|c|c|c|c|c|}
\hline $\begin{array}{l}\text { YearNumber } \\
\text { (Percentage, \%) }\end{array}$ & $\begin{array}{l}2006 \\
n(\%) \\
\end{array}$ & $\begin{array}{l}2007 \\
n(\%)\end{array}$ & $\begin{array}{l}2008 \\
n(\%)\end{array}$ & $\begin{array}{l}2009 \\
n(\%) \\
\end{array}$ & $\begin{array}{l}2010 \\
n(\%)\end{array}$ & $\begin{array}{l}2011 \\
n(\%)\end{array}$ & $\begin{array}{l}2012 \\
n(\%) \\
\end{array}$ & $\begin{array}{l}2013 \\
n(\%) \\
\end{array}$ & $\begin{array}{l}2014 \\
n(\%)\end{array}$ & $\begin{array}{l}2015 \\
n(\%) \\
\end{array}$ & $\begin{array}{l}\text { Total } \\
n(\%) \\
\end{array}$ \\
\hline non-myopia $^{a}$ & $\begin{array}{l}1611 \\
(44.05)\end{array}$ & $\begin{array}{l}1573 \\
(43.51)\end{array}$ & $\begin{array}{l}1521 \\
(41.53)\end{array}$ & $\begin{array}{l}1459 \\
(39.46)\end{array}$ & $\begin{array}{l}1528 \\
(39.21)\end{array}$ & $\begin{array}{l}1471 \\
(38.87)\end{array}$ & $\begin{array}{l}1456 \\
(38.16)\end{array}$ & $\begin{array}{l}1410 \\
(37.23)\end{array}$ & $\begin{array}{l}1386 \\
(36.16)\end{array}$ & $\begin{array}{l}1269 \\
(34.52)\end{array}$ & $\begin{array}{l}14,684 \\
(100)\end{array}$ \\
\hline Boys & $\begin{array}{l}814 \\
(22.26)\end{array}$ & $\begin{array}{l}796 \\
(22.02)\end{array}$ & $\begin{array}{l}772 \\
(21.08)\end{array}$ & $\begin{array}{l}768 \\
(20.77)\end{array}$ & $\begin{array}{l}789 \\
(20.25)\end{array}$ & $\begin{array}{l}786 \\
(20.77)\end{array}$ & $\begin{array}{l}764 \\
(20.02)\end{array}$ & $\begin{array}{l}737 \\
(19.46)\end{array}$ & $\begin{array}{l}744 \\
(19.41)\end{array}$ & $\begin{array}{l}683 \\
(18.58)\end{array}$ & $\begin{array}{l}7653 \\
(20.45)\end{array}$ \\
\hline Girls & $\begin{array}{l}797 \\
(21.79)\end{array}$ & $\begin{array}{l}777 \\
(21.49)\end{array}$ & $\begin{array}{l}749 \\
(20.45)\end{array}$ & $\begin{array}{l}691 \\
(18.69)\end{array}$ & $\begin{array}{l}739 \\
(18.96)\end{array}$ & $\begin{array}{l}685 \\
(18.10)\end{array}$ & $\begin{array}{l}692 \\
(18.13)\end{array}$ & $\begin{array}{l}673 \\
(17.77)\end{array}$ & $\begin{array}{l}642 \\
(16.75)\end{array}$ & $\begin{array}{l}586 \\
(15.94)\end{array}$ & $\begin{array}{l}7031 \\
(18.79)\end{array}$ \\
\hline low myopia & $\begin{array}{l}1180 \\
(32.27)\end{array}$ & $\begin{array}{l}1151 \\
(31.84)\end{array}$ & $\begin{array}{l}1124 \\
(30.69)\end{array}$ & $\begin{array}{l}1052 \\
(28.46)\end{array}$ & $\begin{array}{l}1057 \\
(27.12)\end{array}$ & $\begin{array}{l}969 \\
(25.61)\end{array}$ & $\begin{array}{l}923 \\
(24.19)\end{array}$ & $\begin{array}{l}890 \\
(23.50)\end{array}$ & $\begin{array}{l}854 \\
(22.28)\end{array}$ & $\begin{array}{l}762 \\
(20.73)\end{array}$ & $\begin{array}{l}9962 \\
(26.62)\end{array}$ \\
\hline Boys & $\begin{array}{l}603 \\
(16.49)\end{array}$ & $\begin{array}{l}577 \\
(15.96)\end{array}$ & $\begin{array}{l}571 \\
(15.59)\end{array}$ & $\begin{array}{l}568 \\
(15.36)\end{array}$ & $\begin{array}{l}558 \\
(14.32)\end{array}$ & $\begin{array}{l}539 \\
(14.24)\end{array}$ & $\begin{array}{l}398 \\
(10.43)\end{array}$ & $\begin{array}{l}467 \\
(12.33)\end{array}$ & $\begin{array}{l}461 \\
(12.03)\end{array}$ & $\begin{array}{l}402 \\
(10.94)\end{array}$ & $\begin{array}{l}5144 \\
(13.75)\end{array}$ \\
\hline Girls & $\begin{array}{l}577 \\
(15.78)\end{array}$ & $\begin{array}{l}574 \\
(15.88)\end{array}$ & $\begin{array}{l}553 \\
(15.10)\end{array}$ & $\begin{array}{l}484 \\
(13.09)\end{array}$ & $\begin{array}{l}499 \\
(12.80)\end{array}$ & $\begin{array}{l}430 \\
(11.36)\end{array}$ & $\begin{array}{l}525 \\
(13.76)\end{array}$ & $\begin{array}{l}423 \\
(11.17)\end{array}$ & $\begin{array}{l}393 \\
(10.25)\end{array}$ & $360(9.79)$ & $\begin{array}{l}4818 \\
(12.87)\end{array}$ \\
\hline $\begin{array}{l}\text { moderate } \\
\text { myopia }\end{array}$ & $\begin{array}{l}721 \\
(19.72)\end{array}$ & $\begin{array}{l}740 \\
(20.47)\end{array}$ & $\begin{array}{l}843 \\
(23.02)\end{array}$ & $\begin{array}{l}1002 \\
(27.01)\end{array}$ & $\begin{array}{l}1097 \\
(28.15)\end{array}$ & $\begin{array}{l}1121 \\
(29.62)\end{array}$ & $\begin{array}{l}1211 \\
(31.73)\end{array}$ & $\begin{array}{l}1259 \\
(33.25)\end{array}$ & $\begin{array}{l}1347 \\
(35.14)\end{array}$ & $\begin{array}{l}1399 \\
(38.06)\end{array}$ & $\begin{array}{l}10,740 \\
(28.70)\end{array}$ \\
\hline Boys & $289(7.90)$ & $311(8.60)$ & $332(9.07)$ & $\begin{array}{l}427 \\
(11.55)\end{array}$ & $\begin{array}{l}420 \\
(10.78)\end{array}$ & $\begin{array}{l}512 \\
(13.53)\end{array}$ & $\begin{array}{l}492 \\
(12.89)\end{array}$ & $\begin{array}{l}528 \\
(13.94)\end{array}$ & $\begin{array}{l}501 \\
(13.07)\end{array}$ & $\begin{array}{l}592 \\
(16.10)\end{array}$ & $\begin{array}{l}4273 \\
(11.42)\end{array}$ \\
\hline Girls & $\begin{array}{l}432 \\
(12.81)\end{array}$ & $\begin{array}{l}429 \\
(11.87)\end{array}$ & $\begin{array}{l}511 \\
(13.95)\end{array}$ & $\begin{array}{l}575 \\
(15.55)\end{array}$ & $\begin{array}{l}677 \\
(17.37)\end{array}$ & $\begin{array}{l}609 \\
(16.09)\end{array}$ & $\begin{array}{l}719 \\
(18.84)\end{array}$ & $\begin{array}{l}731 \\
(19.30)\end{array}$ & $\begin{array}{l}846 \\
(22.07)\end{array}$ & $\begin{array}{l}807 \\
(21.95)\end{array}$ & $\begin{array}{l}6467 \\
(17.28)\end{array}$ \\
\hline high myopia & $145(3.96)$ & $151(4.18)$ & $174(4.75)$ & $184(4.98)$ & $215(5.52)$ & $223(5.89)$ & $226(5.92)$ & $228(6.02)$ & $246(6.42)$ & $246(6.69)$ & $\begin{array}{l}2038 \\
(5.45)\end{array}$ \\
\hline Boys & $36(0.98)$ & $36(1.00)$ & $53(1.45)$ & $70(1.89)$ & $86(2.21)$ & $89(2.35)$ & $98(2.57)$ & $84(2.22)$ & 77 (2.01) & $95(2.58)$ & $\begin{array}{l}724 \\
(1.93)\end{array}$ \\
\hline Girls & 109 (2.98) & 115 (3.18) & $121(3.30)$ & $114(3.08)$ & $129(3.31)$ & $134(3.54)$ & $128(3.35)$ & $144(3.80)$ & $169(4.41)$ & $151(4.11)$ & $\begin{array}{l}1314 \\
(3.51)\end{array}$ \\
\hline Total & $\begin{array}{l}3657 \\
(100.00)\end{array}$ & $\begin{array}{l}3615 \\
(100.00)\end{array}$ & $\begin{array}{l}3662 \\
(100.00)\end{array}$ & $\begin{array}{l}3697 \\
(100.00)\end{array}$ & $\begin{array}{l}3897 \\
(100.00)\end{array}$ & $\begin{array}{l}3784 \\
(100.00)\end{array}$ & $\begin{array}{l}3816 \\
(100.00)\end{array}$ & $\begin{array}{l}3787 \\
(100.00)\end{array}$ & $\begin{array}{l}3833 \\
(100.00)\end{array}$ & $\begin{array}{l}3676 \\
(100.00)\end{array}$ & $\begin{array}{l}37,424 \\
(100)\end{array}$ \\
\hline Boys & $\begin{array}{l}1742 \\
(47.63)\end{array}$ & $\begin{array}{l}1629 \\
(45.06)\end{array}$ & $\begin{array}{l}1718 \\
(46.91)\end{array}$ & $\begin{array}{l}1833 \\
(49.58)\end{array}$ & $\begin{array}{l}1853 \\
(47.55)\end{array}$ & $\begin{array}{l}1926 \\
(50.90)\end{array}$ & $\begin{array}{l}1752 \\
(45.91)\end{array}$ & $\begin{array}{l}1816 \\
(47.95)\end{array}$ & $\begin{array}{l}1783 \\
(46.52)\end{array}$ & $\begin{array}{l}1772 \\
(48.20)\end{array}$ & $\begin{array}{l}17,794 \\
(47.55)\end{array}$ \\
\hline Girls & $\begin{array}{l}1915 \\
(52.37)\end{array}$ & $\begin{array}{l}1986 \\
(54.94)\end{array}$ & $\begin{array}{l}1944 \\
(53.09)\end{array}$ & $\begin{array}{l}1864 \\
(50.42)\end{array}$ & $\begin{array}{l}2044 \\
(52.45)\end{array}$ & $\begin{array}{l}1858 \\
(49.10)\end{array}$ & $\begin{array}{l}2064 \\
(54.09)\end{array}$ & $\begin{array}{l}1971 \\
(52.05)\end{array}$ & $\begin{array}{l}2050 \\
(53.48)\end{array}$ & $\begin{array}{l}1904 \\
(51.80)\end{array}$ & $\begin{array}{l}19,630 \\
(52.45)\end{array}$ \\
\hline
\end{tabular}



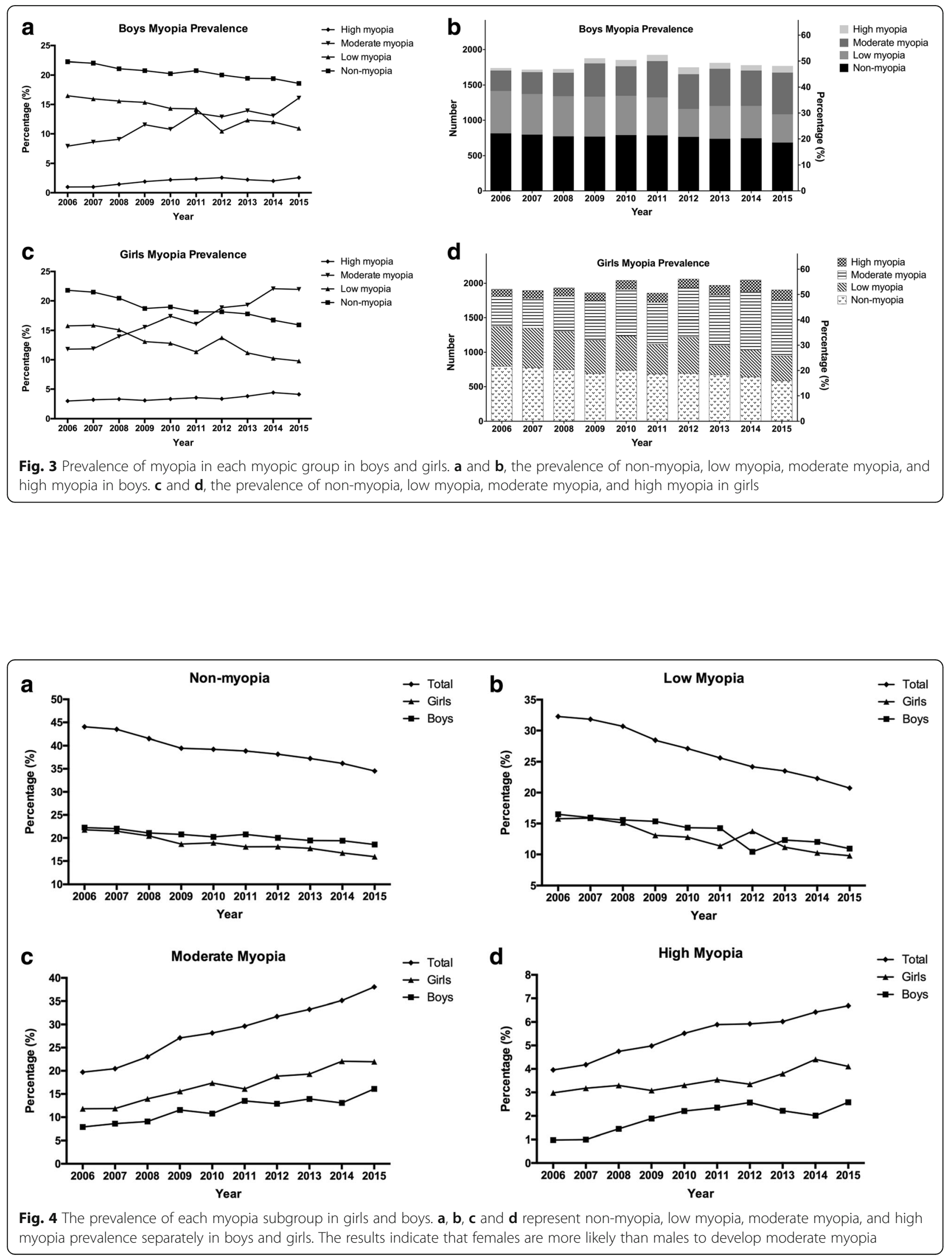
significantly. Finally, girls were significantly more myopic and more likely to have myopia than boys, especially in the moderate and high myopia subgroups.

Myopia is an important disease that causes visual impairment in individuals around the world, especially children $[1,13]$. Correcting an individual's myopia status is the most cost-effective issue in public eye health care $[14,15]$. Moreover, as an often underestimated health condition, myopia is associated with a variety of vision-threatening ocular complications, such as maculopathy, choroidal neovascularization and retinal detachment [16-18].

During recent decades, multiple population-based surveys have been performed in different areas that have reported the prevalence of myopia. For example, the myopia prevalence is $22.3 \%$ in Iran [19], $23.7 \%$ in Western Australia [20], and 28.3\% in Israel [21]. However, the prevalence of myopia is much higher in East Asia, where it has been found to be as high as $84 \%$ in Taiwan [3] and $81.6 \%$ in Singapore [7]. In China, according to the results of the National Survey on the Constitution and Health of Chinese Students, there has been a remarkable increase in the number of individuals with reduced VA, from $50.8 \%$ in 1985 to $79.3 \%$ in 2010 [22]. Additionally, other studies have demonstrated that the prevalence of myopia is higher as $95.5 \%$ in Shanghai [8], $80 \%$ in Shandong [23], and $74.2 \%$ in Beijing [24]. The incidence reported in these studies showed a great deal of variation, but the observed trend indicates that East Asians tend to be more likely to experience a myopic shift in refraction, perhaps because of variations in environment, geography, and other factors $[25,26]$.

Nevertheless, although an abundance of cross-sectional studies have explored the prevalence of myopia in schoolaged children, there have been relatively few longitudinal follow-up studies of any specific group. Several studies have reported on the continuous incidence of myopia; for example, in Taiwan, the prevalence of myopia in 18-yearold children increased from $74 \%$ in 1983 to $84 \%$ in 2004 [3]. Koh et al. conducted a survey in Singapore and found that the overall prevalence of myopia increased in young males from $79.2 \%$ in $1996-1997$ to $81.6 \%$ in $2009-2010$ [7]. In mainland China, a longitudinal study of refractive error was performed in Shunyi District in 2000, and it reported that the annualized incidence of myopia was $7.8 \%$, while the rate of myopic progression was $-0.17 \mathrm{D}$ per year [27, 28]. In 2016, another population-based cross-sectional survey of refractive error was performed in children aged 6 to 15 years old in Chonqing City, Western China, and a subsequent 5-year longitudinal follow-up study reported an annual progression of refraction in a myopic direction of $-0.43 \mathrm{D}$ in this population [12]. However, these studies of prevalence have primarily focused on all school-aged children, including primary school students and students who are up to 18 years old.
As stated in the Introduction, the third year of junior high school (grade 9) and the third year of senior high school (grade 12) are times of particularly strong study pressure. The Guangzhou study showed that there was a significant increase in the prevalence of severely and moderately reduced VA, from $62.5 \%$ in 1988 to $84.1 \%$ in 2007, in grade 12 students [29]. Another survey from the National Survey on the Constitution and Health of Chinese Students in mainland China also showed that the prevalence of reduced VA in 16- to18-year-old subjects significantly increased from $50.8 \%$ in 1985 to $79.3 \%$ in 2010 [22]. In the present study, we performed a 10year longitudinal follow-up study to investigate changes in the prevalence of myopia in the third year of the Haidian District of Beijing, China. This region is associated with the most intense learning stress in Beijing. Similar to a report from the Beijing Childhood Eye Study, we found that the prevalence of myopia in 14 to 16 -year-olds was between $61.9 \%$ and $73 \%$. Our data also showed similar patterns of changes to those observed in previous studies, in that we observed a remarkable and significant increase in the prevalence of myopia from $55.95 \%$ in 2006 to $65.48 \%$ in 2015 . The moderate high myopia subgroup increased the most significantly among all of the subgroups, with an $18.34 \%$ increase.

Our findings that the progression of myopia as also associated with being female and having a higher level of baseline myopia are similar to the findings described in a previous report. Previously, studies in Shunyi [28], Yongchuan [12], Finland [30] and Australia [20] also reported observing an increase in the progression of myopia and a tendency for female individuals to be more or more frequently myopic. In our survey, in which we included both boys and girls, the proportion of students in both low myopia sub-groups significantly decreased between 2006 and 2015, and the two subgroups decreased in parallel. However, there was a significantly higher prevalence of moderate and high myopia in female than in male subjects, who showed an increase from $12.81 \%$ in 2006 to $21.95 \%$ in 2015 , consistent with previous studies $[8,23,31]$. One possible explanation is that girls tend to read and write more and to perform less outdoor exercise [32, 33]. The associated increase in near-eye work predisposes them to developing myopia [32]. The school system is becoming more and more competitive in mainland China, especially in terms of the expectation that students must achieve high scores to enter a high quality senior high school. It has been reported that $12.5 \%$ of students do not participate in any kind of outdoor activity [33, 34]. A recent study from Guangzhou also reported the prevalence of myopia in students increased along with the growth of grade level, which the prevalence of myopia in students in grade 3 was $38.8 \%$, and the rate was increased to $68.4 \%$ in grade 
9 [29]. And the prevalence in grade 9 was also consistent with the findings from our study $65.48 \%$. Previous studies showed that a sort duration of outdoor activities is among a number of factors, such as parental myopia and region of habitation, that have major associations with the prevalence and incidence of myopia in children [35]. In comparisons between the sexes, girls usually spend more time reading and performing near-eye work and with less time engaging in outdoor activities, and this makes them more vulnerable to developing myopia [24].

Several methodological limitations should be acknowledged. For example, in the present study a questionnaire was not used to analyze the presence of possible risk factors for myopia, such as parental myopia, time spent in outdoor activities, and ethnicity. Additionally, we did not measure axial length, which would have complemented our data. Finally, strict statistical randomization was not applied in our survey. Further prospective, large-scale, multi-center studies are therefore required to validate our data.

To our knowledge, this is the first longitudinal study to examine the incidence and progression of myopia in third year students (grade 9, ages 15 to 16 years old) in junior high school in the Haidian District of Beijing, China. During the 10-year study period, from 2006 to 2015, the mean spherical equivalent refractive error and prevalence of myopia significantly increased, and the incidence of myopia also significantly increased. And according to our data, girls were significantly more myopic and more likely to have myopia than boys, especially in the moderate myopia subgroup.

\section{Conclusions}

In the present study, we investigated the prevalence of myopia from 2006 to 2015 in a population of third-year students in junior high school in the Haidian District of Beijing, China. During the past 10 years, the prevalence of myopia significantly increased on an annual basis, especially the moderate and high myopia population. Meanwhile, girls were significantly more myopic and more likely to have myopia than boys. The refractive status and accordingly performed intervention strategies deserves particular attention for the whole society of China.

\section{Additional file}

Additional file 1: The file attached includes the raw data of the refractive status of all individual in the present study, which from 2006 to 2015 in the junior high school in the Haidian District of Beijing, China. In each tab page, the patent ID of the students were recorded by number; the gender was recorded by male $(M=1)$ or female $(F=2)$; the refractive status of the right eye (OD), left eye (OS), and the worse eye were also recorded by diopter. At the end of each tab page, the mean, standard deviation (SD), and median of the refractive status of all individual in each year were also calculated. (XLSX 2605 kb)

\section{Abbreviations}

BCVA: Best-corrected visual acuity; Cl: Confidence intervals; D: Diopters; IQR: Interquartile range; ORs: Odds ratios; RE: Refractive error;

SER: Spherical equivalent refraction; SERE: Spherical equivalent refractive error; VA: Visual acuity

\section{Acknowledgments}

We thank Chunfang ZHANG for her help with the statistical analysis.

\section{Funding}

Not applicable.

Availability of data and materials

The raw data of the refractive status of all individual can be found in Additional file 1 .

\section{Authors' contributions}

Research design: YL, JL; Experiments: YL, PQ; Data analysis: $Y L, J L$; Wrote or contributed to writing the manuscript: $Y L, J L, P Q$; Reviewing the manuscript: $Y L, J L ;$ Grants obtained: Not applicable. We confirmed that all authors $(J L, P Q, Y L)$ have read and approved of the final manuscript.

\section{Competing interests}

The authors declare that they have no competing interests.

\section{Consent for publication}

Informed written consent as obtained from at least one parent or guardian of each child.

\section{Ethics approval and consent to participate}

Ethical approval was obtained from the Ethics Review Board and the Ethics Committee of Peking University People's Hospital. The study adhered to the guidelines of the Declaration of Helsinki.

\section{Publisher's Note}

Springer Nature remains neutral with regard to jurisdictional claims in published maps and institutional affiliations.

Received: 27 July 2016 Accepted: 31 May 2017

Published online: 12 June 2017

\section{References}

1. Morgan IG, Ohno-Matsui K, Saw SM. Myopia. Lancet. 2012;379(9827):1739-48.

2. Pan CW, Ramamurthy D, Saw SM. Worldwide prevalence and risk factors for myopia. Ophthalmic Physiol Opt. 2012;32(1):3-16.

3. Lin LL, Shih YF, Hsiao CK, Chen CJ. Prevalence of myopia in Taiwanese schoolchildren: 1983 to 2000. Ann Acad Med Singap. 2004;33(1):27-33.

4. Matsumura $\mathrm{H}$, Hirai $\mathrm{H}$. Prevalence of myopia and refractive changes in students from 3 to 17 years of age. Surv Ophthalmol. 1999;44(Suppl 1): S109-15.

5. Jung SK, Lee JH, Kakizaki H, Jee D. Prevalence of myopia and its association with body stature and educational level in 19-year-old male conscripts in seoul, South Korea. Invest Ophthalmol Vis Sci. 2012;53(9):5579-83.

6. Lee JH, Jee D, Kwon JW, Lee WK. Prevalence and risk factors for myopia in a rural Korean population. Invest Ophthalmol Vis Sci. 2013;54(8):5466-71.

7. Koh V, Yang A, Saw SM, Chan YH, Lin ST, Tan MM, et al. Differences in prevalence of refractive errors in young Asian males in Singapore between 1996-1997 and 2009-2010. Ophthalmic Epidemiol. 2014;21(4):247-55.

8. Sun J, Zhou J, Zhao P, Lian J, Zhu H, Zhou Y, et al. High prevalence of myopia and high myopia in 5060 Chinese university students in shanghai. Invest Ophthalmol Vis Sci. 2012;53(12):7504-9.

9. Wu LJ, You QS, Duan JL, Luo YX, Liu LJ, Li X, et al. Prevalence and associated factors of myopia in high-school students in Beijing. PLoS One. 2015;10(3):e0120764

10. Kang MT, Li SM, Peng X, Li L, Ran A, Meng B, et al. Chinese eye exercises and myopia development in school age children: a nested case-control study. Sci Rep. 2016;6:28531.

11. Yu S, Diao H, Zeng J. Analysis of the prevalence and situation of myopia in adolescents from South China. Eye Sci. 2015;30(2):53-5. 74 
12. Zhou WJ, Zhang YY, Li H, Wu YF, XU J, Lv S, et al. Five-year progression of refractive errors and incidence of myopia in school-aged children in Western China. J Epidemiol. 2016;26(7):386-95.

13. Rudnicka AR, Kapetanakis W, Wathern AK, Logan NS, Gilmartin B, Whincup $\mathrm{PH}$, et al. Global variations and time trends in the prevalence of childhood myopia, a systematic review and quantitative meta-analysis: implications for aetiology and early prevention. Br J Ophthalmol. 2016;

14. Choo V. A look at slowing progression of myopia. Lancet. 2003;361(9369):1622-3.

15. Repka MX. Prevention of myopia in children. JAMA. 2015;314(11):1137-9.

16. Wong TY, Ferreira A, Hughes R, Carter G, Mitchell P. Epidemiology and disease burden of pathologic myopia and myopic choroidal neovascularization: an evidence-based systematic review. Am J Ophthalmol. 2014;157(1):9-25. e12

17. Xu L, Wang Y, Li Y, Wang Y, Cui T, Li J, et al. Causes of blindness and visual impairment in urban and rural areas in Beijing: the Beijing eye study. Ophthalmology. 2006;113(7):1134 e1131-11.

18. Ohno-Matsui K, Yoshida T. Myopic choroidal neovascularization: natural course and treatment. Curr Opin Ophthalmol. 2004;15(3):197-202.

19. Hashemi H, Rezvan F, Ostadimoghaddam H, Abdollahi M, Hashemi M, Khabazkhoob M. High prevalence of refractive errors in a rural population: 'Nooravaran Salamat' mobile eye Clinic experience. Clin Experiment Ophthalmol. 2013;41(7):635-43.

20. McKnight CM, Sherwin JC, Yazar S, Forward H, Tan AX, Hewitt AW, et al. Myopia in young adults is inversely related to an objective marker of ocular sun exposure: the Western Australian Raine cohort study. Am J Ophthalmol. 2014;158(5):1079-85.

21. Bar Dayan Y, Levin A, Morad Y, Grotto I, Ben-David R, Goldberg A, et al. The changing prevalence of myopia in young adults: a 13-year series of populationbased prevalence surveys. Invest Ophthalmol Vis Sci. 2005;46(8):2760-5.

22. Sun HP, Li A, Xu Y, Pan CW. Secular trends of reduced visual acuity from 1985 to 2010 and disease burden projection for 2020 and 2030 among primary and secondary school students in China. JAMA Ophthalmol. 2015; 133(3):262-8.

23. Wu JF, Bi HS, Wang SM, Hu YY, Wu H, Sun W, et al. Refractive error, visual acuity and causes of vision loss in children in Shandong, China. The Shandong children eye study. PLoS One. 2013;8(12):e82763,

24. You QS, Wu LJ, Duan JL, Luo YX, Liu LJ, Li X, et al. Prevalence of myopia in school children in greater Beijing: the Beijing childhood eye study. Acta Ophthalmol. 2014;92(5):e398-406.

25. Aller TA. Clinical management of progressive myopia. Eye (Lond). 2014;28(2): 147-53.

26. Ramamurthy D, Lin Chua SY, Saw SM. A review of environmental risk factors for myopia during early life, childhood and adolescence. Clin Exp Optom. 2015;98(6):497-506.

27. Zhao J, Pan X, Sui R, Munoz SR, Sperduto RD, Ellwein LB. Refractive error study in children: results from Shunyi District, China. Am J Ophthalmol. 2000;129(4):427-35.

28. Zhao J, Mao J, Luo R, Li F, Munoz SR, Ellwein LB. The progression of refractive error in school-age children: Shunyi district, China. Am J Ophthalmol. 2002;134(5):735-43.

29. Guo L, Yang J, Mai J, Du X, Guo Y, Li P, et al. Prevalence and associated factors of myopia among primary and middle school-aged students: a school-based study in Guangzhou. Eye (Lond). 2016;30(6):796-804.

30. Parssinen $\mathrm{O}$, Kauppinen M, Viljanen A. The progression of myopia from its onset at age 8-12 to adulthood and the influence of heredity and external factors on myopic progression. A 23-year follow-up study. Acta Ophthalmol. 2014:92(8):730-9.

31. Guo YH, Lin HY, Lin LL, Cheng CY. Self-reported myopia in Taiwan: 2005 Taiwan National Health Interview Survey. Eye (Lond). 2012;26(5):684-9.

32. Saw SM, Zhang MZ, Hong RZ, Fu ZF, Pang MH, Tan DT. Near-work activity, night-lights, and myopia in the Singapore-China study. Arch Ophthalmol. 2002;120(5):620-7.

33. He M, Xiang F, Zeng Y, Mai J, Chen Q, Zhang J, et al. Effect of time spent outdoors at school on the development of myopia among children in China: a randomized clinical trial. JAMA. 2015;314(11):1142-8.

34. Rose KA, Morgan IG, Ip J, Kifley A, Huynh S, Smith W, et al. Outdoor activity reduces the prevalence of myopia in children. Ophthalmology. 2008;115(8): 1279-85.

35. Wu PC, Tsai CL, Wu HL, Yang YH, Kuo HK. Outdoor activity during class recess reduces myopia onset and progression in school children. Ophthalmology. 2013;120(5):1080-5

\section{Submit your next manuscript to BioMed Central and we will help you at every step:}

- We accept pre-submission inquiries

- Our selector tool helps you to find the most relevant journal

- We provide round the clock customer support

- Convenient online submission

- Thorough peer review

- Inclusion in PubMed and all major indexing services

- Maximum visibility for your research

Submit your manuscript at www.biomedcentral.com/submit
Biomed Central 